\title{
ANDROGEN RECEPTOR POSITIVITY IN TRIPLE-NEGATIVE BREAST CANCER
}

\author{
P. Jovita M. Martin ${ }^{1}$, Kalaichelvi K², Suresh Kumar ${ }^{3}$
}

${ }^{1}$ Assistant Professor, Department of Medical Oncology, SRMC, Chennai, Tamilnadu, India.

2Professor, Department of Medical Oncology, Madras Medical College, Chennai, Tamilnadu, India.

${ }_{3}^{3}$ Associate Professor, Department of Medical Oncology, Madras Medical College, Chennai, Tamilnadu, India.

\section{ABSTRACT}

\section{BACKGROUND}

Triple-Negative Breast Cancers (TNBC) is an enigmatic group of breast cancers with rising trend. The presence of Androgen Receptor (AR) in Oestrogen Receptor (ER) negative cases is 30\%, in TNBC the AR positivity is $<20 \%$.

Aim: This study is done to know the percentage of AR in TNBC in this population.

\section{MATERIALS AND METHODS}

This is a retrospective descriptive study. The total breast cancer patients between the periods of October 2014 and February 2014 were 734 cases. 72 cases were triple-negative breast cancer cases as demonstrated by the immunohistochemistry. Androgen receptor was considered positive if $>10 \%$ of cells showed positivity on immunohistochemistry.

\section{RESULTS}

Androgen receptor is negative amongst a majority of $88 \%$ of patients with $12 \%$ remaining AR positive, of which $8 \%$ is high, 3 medium and 1 low positive. The percentage of AR positivity in TNBC in this study concurs with the literature findings.

\section{CONCLUSION}

This explains the importance of the same in TNBC, as it seems to be an important avenue for therapeutic targeting, because this group of patients do not have much options for treatment. Further studies with the use of androgen receptor blockade through drugs like Bicalutamide/Enzalutamide/Abiraterone in AR-positive TNBC could be studied to know the survival improvement.

\section{KEY WORDS}

Androgen Receptor, Triple-Negative Breast Cancer.

HOW TO CITE THIS ARTICLE: Martin PJM, Kalaichelvi K, Kumar S. Androgen receptor positivity in triple-negative breast cancer. J. Evolution Med. Dent. Sci. 2018;7(36):3959-3963, DOI: 10.14260/jemds/2018/885

\section{BACKGROUND}

Triple-Negative Breast Cancer (TNBC) is defined as negative for ER, PgR and HER-2/neu (with the finding of $<1 \%$ of tumour cell nuclei immunoreactive in immunohistochemistry, in the presence of the evidence of the sample that can express ER, PgR or HER-2/neu respectively as positive intrinsic controls). TNBC occurrence is on the rising trend. This has been recognised as a unique subgroup of breast cancer. TNBC occurrence is around $15-20 \%$ of all breast cancers. ${ }^{1,2}$ The presence of AR in ER negative cases is $30 \%$, in TNBC the AR positivity is $<20 \% 3,4,5,6,7,8$ (some studies have even accounted that the overall AR positivity in breast cancer is $60-70 \%$ ).

The Luminal AR is a subgroup expressing Androgen receptors. By demonstrating AR positivity in breast cancer, it is a prognostic and predictive factor. $9,10,11$ AR +ve, TNBC are lower grade tumours showing good response to neoadjuvant chemotherapy in Locally Advanced Breast Cancer (LABC).

Therapeutic targeted agents such as Bicalutamide, an anti-androgen can be used against AR in AR expressing TNBC.

'Financial or Other Competing Interest': None.

Submission 29-05-2018, Peer Review 21-08-2018,

Acceptance 27-08-2018, Published 03-09-2018.

Corresponding Author:

P. Jovita M. Martin

AG Alsa Deer Park

\#108, Velechery Main Road,

Guindy, Chennai-32, Tamilnadu, India.

E-mail: jovimartin4@gmail.com

DOI: $10.14260 /$ jemds $/ 2018 / 885$
The AR positivity may reflect the natural history of the tumour (prognostic factor) and the likely response to treatment (predictive factor) added to this can be used as a therapeutic target.4,5 AR positivity is a potential target for TNBC, but only accounts to $<20 \%$ of TNBC. $4,5,6,7,8$

\section{Objective}

Triple-Negative Breast Cancer (TNBC) is an enigmatic group of breast cancer with rising trend. The presence of Androgen Receptor (AR) in Oestrogen Receptor (ER) negative cases is $30 \%$ and in TNBC the AR positivity is $<20 \%$. This study is done to know the percentage of $A R$ in TNBC in this population.

\section{MATERIALS AND METHODS}

This is a retrospective descriptive study. The total breast cancer patients between the period of October 2014 and February 2015 were 734 cases. 72 cases were triple-negative breast cancer cases as demonstrated by the immunohistochemistry. Through the immunohistochemistry method using Dako reagents, the presence of Androgen receptor in the above group of 72 patients were studied.

For performance of the IHC staining for AR, antigen retrieval was performed as follows: Five-micron sections are deparaffinised and rehydrated to deionised water. They are heated in citrate buffer ( $\mathrm{pH} 6.0)$ using an electric pressure cooker for three minutes at 12 - 15 pounds Per Square Inch (PSI) at approximately 120 degrees Celsius. They are then cooled for 10 minutes prior to immunostaining. 
All slides were loaded onto an automated system (DAKO Autostainer plus, DAKO) and exposed to 3\% hydrogen peroxide for 5 minutes, incubated with primary antibody for 30 minutes with labelled polymer for 30 minutes, 3, 3'diaminobenzidine (DAB) as chromogen for five minutes and then with haematoxylin as counterstain for five minutes.

These incubations are performed at room temperature; between incubation sections are washed with Tris-Buffered Saline (TBS). Cover slipping was performed using the TissueTek SCA (Sakura Finetek) Coverslipper. Positive controls of known positive tissues (Prostate cancer) and negative controls with primary antibody replaced with TBS were run with the patient slides. Samples were scored positive for AR when at least $10 \%$ of the nuclei of tumour cells were immunoreactive. Further positivity of AR were categorised as low positive $(<10 \%$ of the nuclei of tumour cells were immunoreactive), medium positive (about $10 \%$ of the nuclei of tumour cells were immunoreactive) and high positive ( $>10 \%$ of the nuclei of tumour cells were immunoreactive) (Fig. 1, 2).

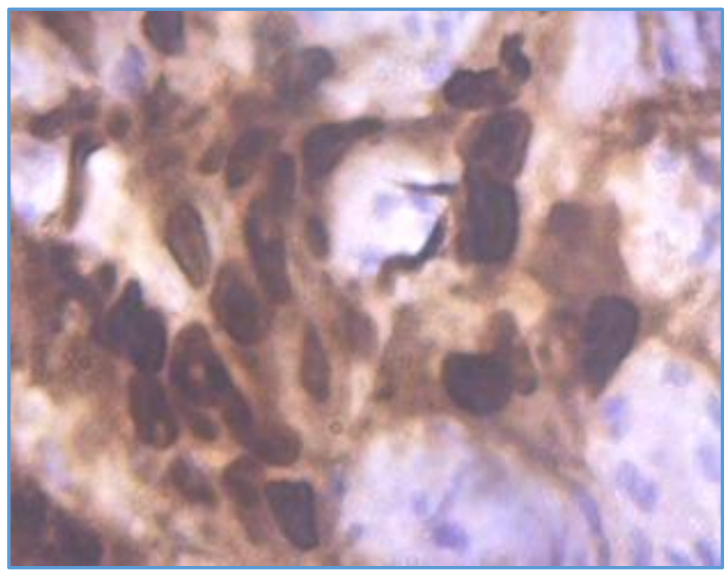

AR Positive in High Magnification

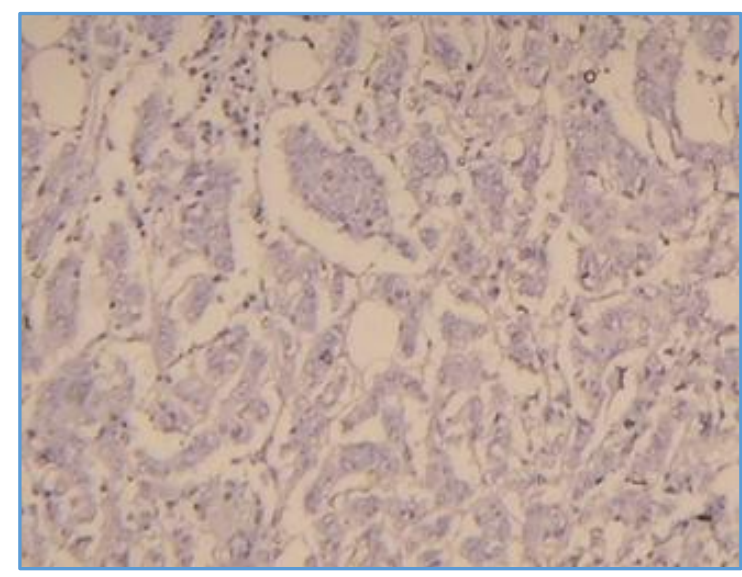

AR Negative

\section{Methods}

The results obtained were recorded in an Excel format. AR presence was demonstrated in TNBC correlated with the pathological parameters and results. Continuous data are expressed as mean \pm standard deviation (SD) and categorical data as frequency counts (percentages).
Data was analysed using the statistical software SPSS version 13.

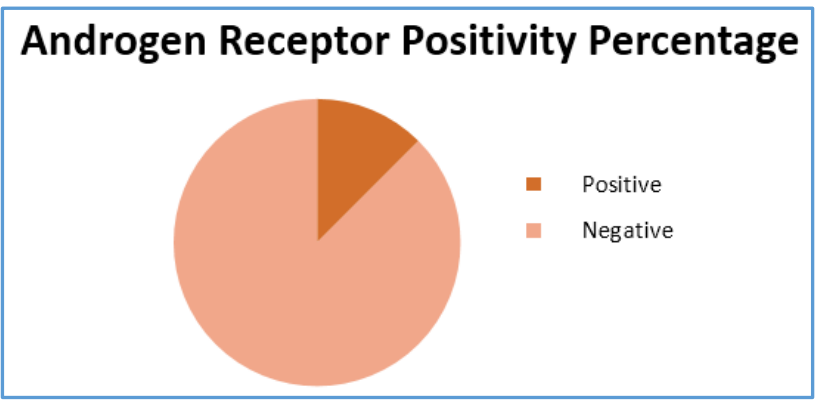

The total numbers of AR positive cases were 9/ 72 (12.5\%). This is in concordance with the literature data that AR is $<20 \%$ positive in TNBC. This helps us understand that AR positivity in TNBC warrants more study and therapeutic exploitation in order to obtain clinical benefit for this subgroup of patients.

\section{RESULTS}

In the review of literature, the premenopausal status has been associated with increased incidence of triple-negative breast cancer. ${ }^{12,13}$ Negative AR is found in pre-, post- and peri-menopausal stages. A high positive AR is also found in all stages of menopause. Moderately positive AR is found only in pre- and peri-menopausal stage, while low positive AR is found only in post- and peri-menopausal stage cases (Graph1). Triple-negative breast cancer is usually of high grade. ${ }^{14}$ The studies show $84 \%$ of TNBC in grade III. ${ }^{15-22}$ In this study, both positive and negative AR is found in all irrespective of the grades with the only exception of moderately positive AR being found in Grade 2 and Grade 3 cases only (Graph-2). Studies also show most TNBC tumours were $>2 \mathrm{~cm} .{ }^{15-22} \mathrm{In}$ this study, AR is found highly positive in Cancer Stages IIA and above. It remains negative in Stages IA and IB. Moderately positive AR is found in Cancer Stages IIIB and IV only. Low positive AR is found in Stages IB, IIA, IIIB and IIIC only (Graph-3). The literature review shows $40 \%$ are positive for axillary lymph node. ${ }^{21,22}$ In this study, $<3 \mathrm{LN}$ had maximum AR positivity of $6.9 \%$ out of $58.3 \%$. Therefore, it can be said that nodal positivity of lower numbers has more chance of AR positivity (Graph 4). The presence of AR in ER negative cases is $30 \%$, in TNBC the AR positivity is $<20 \% 3,3,4,6,6,8$ The Androgen receptor positivity percentage of this set of triple negative patients was compared with the data in the literature. ${ }^{23-34}$ Androgen receptor was considered positive if $>10 \%$ of cells showed positivity in immunohistochemistry. The total numbers of AR positive cases were $9 / 72(12.5 \%)$. This is in concordance with the literature data that AR is $<20 \%$ positive in TNBC. Androgen receptor positivity was further graded as low, medium and high positivity (Tab 1). This explains the significance of AR positivity in TNBC, as it seems to be an important avenue for therapeutic targeting, because this group of patients do not have much options for treatment. Further studies with the use of androgen receptor blockade through drugs like Bicalutamide in AR-positive TNBC could be studied to know the survival improvement. 


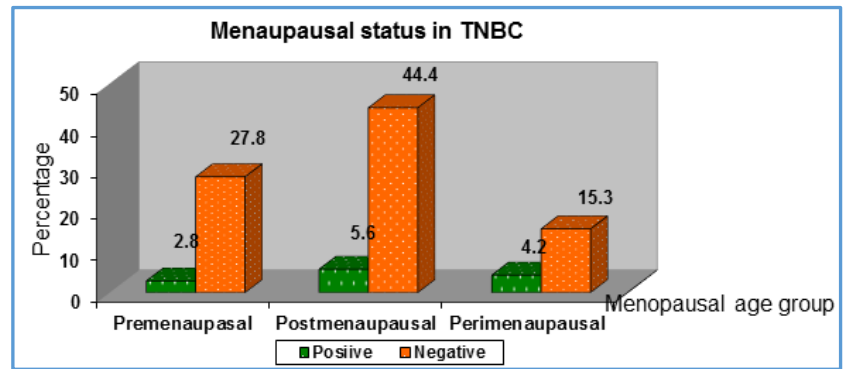

Graph 1

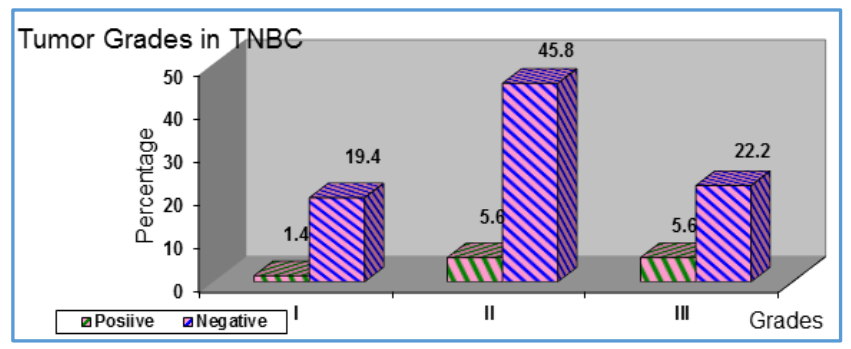

Graph 2

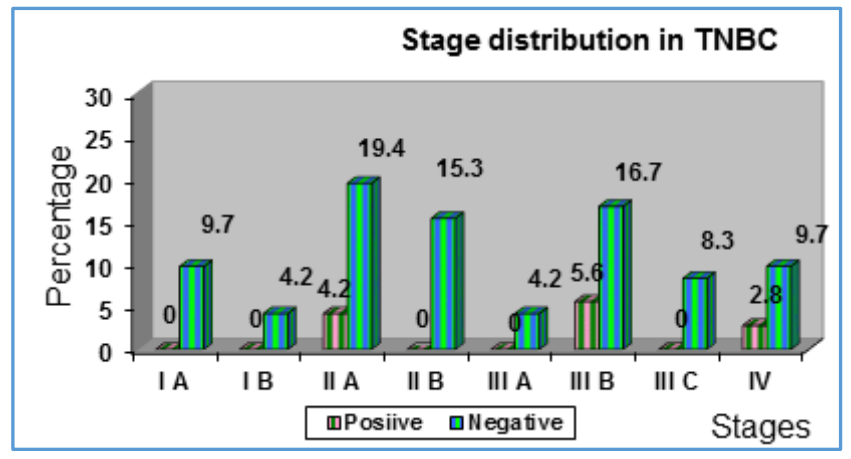

Graph 3

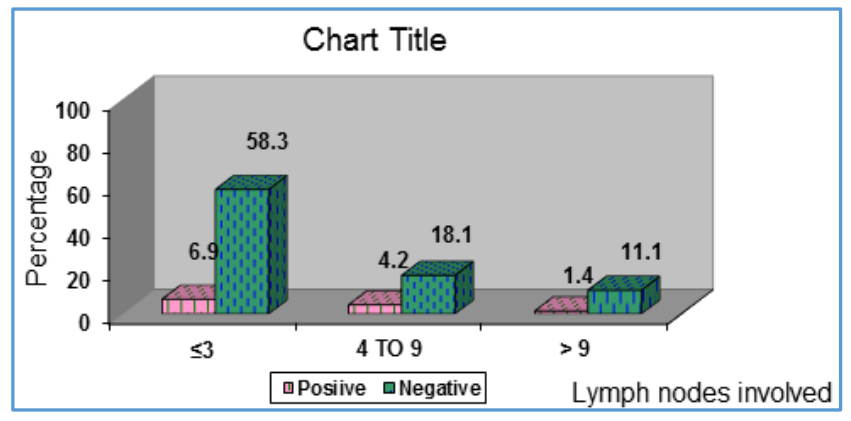

Graph 4

\section{Androgen Receptor Degree of Positivity}

\begin{tabular}{|c|c|c|}
\hline & Number & Percent \\
\hline High positive & 4 & 5.6 \\
\hline Medium positive & 3 & 4.2 \\
\hline Low positive & 2 & 2.8 \\
\hline Negative & 63 & 87.5 \\
\hline Total & $\mathbf{7 2}$ & $\mathbf{1 0 0 . 0}$ \\
\hline \multicolumn{3}{|c|}{ Table 1 } \\
\hline
\end{tabular}

Androgen receptor overall positivity.

\section{DISCUSSION}

Breast cancer cases with ER positivity is about 70\%, HER$2 /$ neu positivity is about $15 \%$ and TNBC is about $15 \%$. The occurrence of AR in TNBC has recently drawn attention recently. One-third of ER negative cases and one-third of BRCA positive cases with high-grade invasive cancers have AR expression. ${ }^{35}$

Androgens are necessary precursors of Oestrogen synthesis in the ovary. Androgens are secreted by both ovaries and adrenals. The main Androgen is secreted as Androgen dehydroepiandrosterone sulfate and nonsulphated forms (DHEAS or DHEA respectively) inhibits growth of breast cancer. ${ }^{36,37,38}$

There are three hypotheses for the risk of breast cancer-

I. Ovarian hyperandrogenism/ luteal inadequacy hypothesis,37 Grattarola 1960: The risk of breast cancer increases with excess ovarian androgens, chronic anovulation, reduction of luteal phase progesterone. There is direct increase in the serum androgen and the metabolites of androgen in serum and urine, which has an impact on the breast tissue increasing cancer risk.

II. Oestrogen plus progesterone hypothesis ${ }^{39}$ MC Pike 1993: Increased levels of oestrogen and progesterone causes increased proliferation during the luteal phase of menstrual cycle.

III. Oestrogen alone hypothesis 40 SF Doisneau-Sixou et al 2003: The increased levels of oestrogen can promote breast tumour development and growth.

The dominant effect of androgens on oestrogen-related tumours is antiproliferative and a decrease in AR-mediated effects might favour tumorigenesis. ${ }^{36,23}$

Hence, AR is a potential target for breast cancer. ${ }^{24}$ AR expression correlates with better prognosis for both primary and metastatic cancer.

\section{ER Negative Subtypes}

The ER negative group of breast cancers consists of multiple subtypes (6 subtypes). Hence, these tumours are ER negative, PR negative and HER-2 negative on clinical assays. So they are nick named 'triple-negative tumours.' Most triplenegative breast cancers are basal-like, whereas most basallike tumours are triple negative. The microarray defined six subgroups of TNBC are-

1. Basal-like 1.

2. Basal-like 2.

3. Immunomodulatory.

4. Mesenchymal-like.

5. Mesenchymal stem-like.

6. Luminal AR.

Breakdown of TNBC by Microarray Defined Subtypes as assigned by PAM (Fig. 7).

TNBC is defined by the absence of a target; therefore, there is absence of a tailored targeted therapy, leaving its management depend on conventional cytotoxic regimens (Tab 2). This group of patients poses a major challenge to the physicians and patients. Hence, there is increasing research on this group of patients. Often TNBC is the proxy term used interchangeably with basal-like breast cancer.

The initial pilot study was done to demonstrate AR positive cases in TNBC with 72 patients, where we found $12 \%$ of cases were AR positive. The extension of the study to 142 
patients was not only to check the AR positivity, but also to correlate with other variables. The correlation of androgen receptor positivity in TNBC with clinical parameters such as age, histopathological parameters, hormone receptor status and nodal status were analysed in the breast cancer population reported to us. The very reason for this study is to find out which group of this heterogeneous TNBC would benefit with an alternative agent specific for its group, as we know that TNBC is known for its aggressive behaviour on recurrence with very little on our platter to offer the patient in a relapsed setting. ${ }^{23-34}$ The next step of the study is to prognosticate this subset of patients and possibly enroll them in a trial using anti-androgens such as Bicalutamide/Enzalutamide/Abiraterone acetate. ${ }^{30}$ However, as our centre is a tertiary care centre with patients flocking from various villages. Hence, the challenge we might face is that not all patients would continue treatment and follow-up in our centre, but might opt to do the same in their hometown. This would make our follow-up study and trial with anti-androgens on the AR-positive TNBC patients rather difficult.

\section{CONCLUSION}

In this study, the Androgen receptor positivity was seen in peri-menopausal and post-menopausal age groups. The occurrence is equally spread out in all grades of tumour, but more in Grade II and III. AR positivity was seen more in locally advanced breast cancer. AR positivity was seen more in cases with $<3 \mathrm{LN}$. There was no correlation between LVI. All cases in this study received chemotherapy. The percentage of AR positivity in TNBC in this study concurs with the literature findings. Hence, more studies on AR positive cases in TNBC are warranted so that the therapeutic exploitation might render us augmented clinical benefit for this subgroup of patients.

\section{REFERENCES}

[1] Parkin M, Bray F, Ferlay J, et al. Global cancer statistics, 2002. CA Cancer J Clin 2005;55(2):74-108.

[2] Bertucci F, Finetti P, Birbaum D. Basal breast cancer: a complex and deadly molecular subtype. Curr Mol Med 2012;12(1):96-110.

[3] Park S, Koo J, Park HS, et al. Expression of androgen receptors is primary breast cancer. Ann Oncol 2010;21(3):488-92.

[4] Trivers KF, Lund MJ, Porter PL, et al. The epidemiology of triple-negative breast cancer, including race. Cancer Causes Control 2009;20(7):1071-82.

[5] Lin NU, Vanderplas A, Hughes ME, et al. Clinicopathologic features, patterns of recurrence and survival among women with triple-negative breast cancer in the National Comprehensive Cancer Network. Cancer 2012;118(22):5463-72.

[6] Hardin C, Pommier R, Calhoun K, et al. A new harmonal therapy for estrogen receptor-negative breast cancer. World J Surg 2007;31(5):1041-6.

[7] Mishra AK, Agrawal U, Negi S, et al. Expression of androgen receptor in breast cancer \& its correlation with other steroid receptors \& growth factors. Indian J Med Res 2012;135(6):843-52.
[8] Adamo B, Anders CK. Stratifying triple-negative breast cancer: Which definition(s) to use? Breast Cancer Research 2011;13(2):105.

[9] Hanley KZ, Wang J, Tang P, et al. Lack of expression of androgen receptor may play a critical role in transformation from in situ to invasive basal subtype of high-grade ductal carcinoma of the breast. Hum Pathol 2008;39:386-92.

[10] Park S, Koo JS, Kim MS, et al. Androgen receptor expression is significantly associated with better outcomes in estrogen receptor-positive breast cancers. Annals of Oncology 2011;22(8):1755-62.

[11] Bryan RM, Mercer RJ, Bennett RC, et al. Androgen receptors in breast cancer. Cancer 1984;54(11):243640.

[12] Diaz-Chico NF, Rodriguez GF, Gonzalez A, et al. Androgens and androgen receptors in breast cancer. Journal of Steroid Biochemistry \& Molecular Biology 2007;105(1-5):1-15.

[13] Hu R, Dawood S, Holmes MD, et al. Androgen receptor expression and breast cancer survival in postmenopausal women. Clin Cancer Res 2011;17(7):1867-74.

[14] Lachapelle J, Foulkes WD. Triple negative and basal like breast cancer implications for oncologists. Curr Oncol 2011;18(4):161-4.

[15] Millikan RC, Newman B, Tse CK, et al. Epidemiology of basal-like breast cancer. Breast Cancer Res Treat 2008;109(1):123-39.

[16] Carey LA, Perou CM, Livasy CA, et al. Race, breast cancer subtypes and survival in the Carolina Breast Cancer Study. JAMA 2006;295(21):2492-502.

[17] Livasy CA, Karaca G, Nanda R, et al. Phenotypic evaluation of the basal-like subtype of invasive breast carcinoma. Mod Pathol 2006;19(2):264-71.

[18] Pristauz G, Petru E, Stacher E, et al. Androgen receptor expression in breast cancer patients tested for BRCA1 and BRCA 2 mutations. Histopathology 2010;57(6):877-84.

[19] Secreto G, Toniolo P, Pisani P, et al. Androgens and breast cancer in premenopausal women. Cancer 1989;49:471-6.

[20] Grattarola R. The premenstrual endometrial pattern of women with breast cancer. A study of progestational activity. Cancer 1964;17:1119-22.

[21] Page JH, Colditz GA, Rifai N, et al. Plasma adrenal androgens and risk of breast cancer in premenopausal woman. Cancer Epidemiol Biomarkers Prev 2004;13(6):1032-6.

[22] Pike MC, Spicer DV, Dahmoush L, et al. Estrogens, progestogens, normal breast cell proliferation and breast cancer risk. Epidemiology 1993;15(1):17-35.

[23] Kaufman PA. Eribulin mesylate versus capecitabine in patients with locally advanced or metastatic breast cancer previously treated with anthracyclines and taxane. J Clin Oncol 2012: p. 6.

[24] Miller K, Wang M, Gralow J, et al. Paclitaxel plus bevacizumab versus paclitaxel alone for metastatic breast cancer. N Engl J Med 2007;357(26):2666-76.

[25] Rugo HS. Phase II study of weekly albumin-bound paclitaxel for patients with metastatic breast cancer. Abstract CRA1002, ASCO 2012. 
[26] Carey LA, Rugo HS, Marcom PK, et al. TBCRC 001: randomized phase II study of cetuximab in combination with carboplatin in stage IV triplenegative breast cancer J Clin Oncol 2012;30(21):261523.

[27] Brufsky A, Valero V, Tiangco B, et al. Impact of Bevacizumab (BEV) on efficacy of second-line chemotherapy (CT) for triple-negative breast cancer (TNBC): analysis of RIBBON-2. Journal of Clinical Oncology, ASCO Annual Meeting Abstracts Part 1. 2011;29(Suppl 15):1010.

[28] Von Minckwitz G, Untch M, Blohmer JU, et al. Definition and impact of pathologic complete response on prognosis after neoadjuvant chemotherapy in various intrinsic breast cancer subtypes. Journal of Clinical Oncology 2012;30(15):1796-804.

[29] Burstein HJ. Bevacizumab for advanced breast cancer: all tied up with a RIBBON? J Clin Oncol 2011;29(10):1232-5.

[30] Gucalp A, Tolaney S, Isakoff S, et al. Endocrine biomarkers in response to AR-inhibition with bicalutamide for the treatment of AR (+), ER/PR(-) metastatic breast cancer (MBC) (TBCRC011). Cancer Res 2012;72(Suppl 24): Abstract No. P6-05-02.

[31] O'Shaughnessy J, Osborne C, Pippen J, et al. Efficacy of BSI-201, a poly (ADP-ribose) polymerase-1 (PARP1) inhibitor, in combination with gemcitabine/ carboplatin $(\mathrm{G} / \mathrm{C})$ in patients with metastatic triplenegative breast cancer (TNBC): results of a randomized phase II trial. J Clin Oncol 2009;27(Suppl 18):Abstract 3.9.

[32] O'Shaughnessy J, Osborne C, Pippen JE, et al. Iniparib plus chemotherapy in metastatic triple-negative breast cancer. N Engl J Med 2011;364:205-14.
[33] Tutt A, Robson M, Garber JE, et al. Oral poly (ADPribose) polymerase inhibitor olaparib in patients with BRCA1 or BRCA2 mutations and advanced breast cancer: a proof-of-concept trial. Lancet 2010;376(9737):235-44.

[34] Melhem-Bertrandt A, Chavez-Macgregor M, Lei X, et al. Beta-blocker use is associated with improved relapsefree survival in patients with TNBC. Originally published by the American Society of Clinical Oncology. J Clin Oncol 2011;29(19):2645-52.

[35] Doisneau-Sixou SF, Sergio CM, Carroll JS, et al. Estrogen and antiestrogen regulation of cell cycle progression in breast cancer cells. Endocr Relat Cancer 2003;10(2):179-86.

[36] Agoff SN, Swanson PE, Linden H, et al. Androgen receptor expression in estrogen receptor-negative breast cancer. Immunohistochemical, clinical and prognostic associations. Am J Clin Pathol 2003;120(5):725-31.

[37] Prat A, Parker JS, Karginova O, et al. Phenotypic and molecular characterization of the claudin-low intrinsic subtype of breast cancer. Breast Cancer Res 2010;12(5):R68.

[38] Teschendorff AE, Miremadi A, Pinder SE, et al. An immune response gene expression module identifies a good prognosis subtype in estrogen receptor negative breast cancer. Genome Biol 2007;8(8):R157.

[39] Parker PA. Breakdown of TNBC by microarray defined subtypes as assigned. J Clin Onc 2009;27:1160-7.

[40] Perez EA, Patel T, Moreno-Aspitia A. Efficacy of ixabepilone in ER/PR/HER2-negative (triple negative) breast cancer. Breast Cancer Res Treat 2010;121(2):261-71. 